\title{
KITAP TANITIMI
}

\author{
[BOOK REVIEW]
}

DoĞU AKdeniz'de Amphoralar, Hakan Öniz, 218 sayfa, 22 numaralandırılmış figür (ve daha birçok sayısız), 3 numaralandırılmış harita (ve daha birçok sayısız), Arkeoloji ve Sanat Yayınları, İstanbul, 2016, ISBN 978-6053964247.

İnsanlık tarihi sürecinde deniz ve denizcilik; toplumların gelişmesinde önemli bir yer edinmiş, insanlığa ticaret, ulaşım veya savaş için kara üzerindeki seyahatten daha fazla hareketlilik ve nakliye için en ekonomik koşulları sağlamıştır. Deniz taşımacilığı antik dönemde toplumlararası etkileşimdeki en önemli araçlardan biridir. Ticari amphoralar ise üretim modelleri gereği antik dönem deniz taşımacilı̆̆ında özel bir yer edinmiştir. Günümüz deniz taşımacıl1ğında kullanılan konteynerlerle karşsış̧ıtırılabilinecek pişmiş topraktan üretilmiş ticari amphoralar, antik dönemde şarap ve zeytinyağının başı çektiği ürünlerin yanı sıra, sıvı katrandan cevize çeşitli türlerdeki zirai ya da endüstriyel ürünlerin nakliyesinde kullanılmışlardır. Seçkinlerin kullanımına sunulan bezemeli ve yüksek kaliteli günlük kullanım seramiklerinden farklı olarak, ticari amphoralar taşıdıkları ürünler nedeniyle tüketim merkezlerinde kendilerine alıc bulmuştur. Yani, diğer seramik tiplerinden farklı olarak, kendileri bir emtia değil ambalajı oldukları ürünler nedeniyle antik dönem pazarında dolay11 bir şekilde kendilerine yer edinmişlerdir. Bu durumda, asıl önemli olan formlarından ziyade içerikleridir; ticari amphoraların kendisini değil, taşıdıkları emtiayı tecimsel bir ürün olarak değerlendirmek gerekir. Ticari amphoralara bu açıdan bakıldığında, onların özellikle toplumlararası ticari ilişkilerin anlaşılmasında, üretici ve tüketici kent devletleri ya da -daha geniş bir ölçekte- bölgeler arasındaki üretim ve tüketim modellerinin belirlenmesine önemli veriler sundukları görülür. Bu ve benzeri nedenlerden ötürü, ticari amphoralara olan akademik ilgi yüz yılı aşkın bir süre öncesinde başlamış̧ır. Bu ilgi son yillarda artarak devam etmektedir.

Doğu Akdeniz ve Ege havzasinda bulunan ticari amphoralar, Tunç Çağı'ndan Ortaçağ’daki kullanımlarının sonuna kadar olan uzun tarihleri boyunca derinlemesine incelenmiştir. Ancak özellikle Anadolu'nun Ege ve Akdeniz kıyı şeridindeki yerleşim yerlerinden elde edilen yeni materyallerin yayınlanmasıyla ilgili hâlâ önemli boşluklar bulunur. 2016 y1lında Hakan Öniz tarafından yayınlanan "Doğu Akdeniz'de Amphoralar" isimli yayın bu bağlamda dikkat

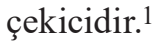

Kitap dizin ve kaynakça bölümleri hariç yirmi bölümden oluşmaktadır. Birinci bölümü oluşturan giriş başlı̆̆ının (sayfa 1-2) ardından ikinci bölümde okuyucuya amphoranın tanımı yapı1mıştır. Yazar üç ve on üçüncü bölümler arasında (sayfa 3-26), genellikle iki paragrafı geçmeyen on bir ayrı kısa bölümde, pişmiş toprağın insan hayatına girişi, çömlekçi çarkı, amphoralarda taşınan ürünler, yazitlar, mühürleme, şarap yapımı ve nakliye gibi amphora çalışmalarının çeşitli yönlerine oldukça kısa bir şekilde değinmiştir. Ancak yazarın, kitabın başlığıyla doğrudan ya da dolaylı ilgisi olmayan "pişmiş toprağın insan hayatına girişi”", "çömlekçi çarkı" ve "geleneksel seramik üretimi" gibi başlıkları neden bu kitabın içerisine aldığı anlaşılamamıştır. Yayında ele alınan amphoraların hepsi "ticari" amphoralardır ki kitap baş̧ı̆̆ı da bu şekilde tanımlayıcı bir sıfata ihtiyaç duymaktadır. Çünkü yazar sayfa 6, figür 4'te Küllüoba'da bulunan ve MÖ 2400-2300 y1llarına tarihlendirilen "ticari" olmayan bir amphorayı "en erken" örneklerden biri olarak referans göstermiştir.

"Amphora" kelimesi antik Yunanca " $\alpha \mu \varphi \imath "$ (kar-

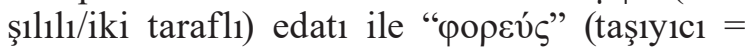

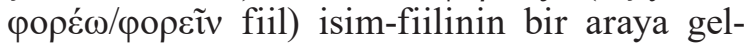
mesiyle oluşturulan ỏ̆

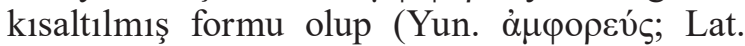
amphora) "karşlıkl1/iki taraflı taşınan" anlamına gelmektedir. Yani, sadece semantik açıdan bakıllırsa iki kulpu olan ve karşıllkkl tutularak taşınan her kap için teoride bu isim kullanılabilir. Ancak, bu kitabın ana konusunu oluşturan amphoraların tümü "ticari" olarak tanımlanan sınıfa girmektedir. ${ }^{2}$ Kitabın başlı̆̆ındaki

1 Söz konusu kitabın yine aynı yılda, Oxford'ta bulunan Arxaeopress yayın evinde "Amphorae in the Eastern Mediterranean" başlıklı İngilizce bir baskısı da yapılmıştır. Stella Demesticha tarafından 2017 yılında International Journal of Nautical Archaeology dergisinin 46/2 sayısının 261-262 sayfalarında İngilizce baskısına bir "review" yazılmıştır.

2 Farklı amphora tipleri için, bk. Bentz 1998. Batı yamacı tekniğinde yapılmış amphoralar için, bk. Rotroff 2006: 85-89. 
bu sıfatın eksikliği metin içerisinde-Küllüoba örneğinde olduğu gibi- görülmekte ve tanım kargaşasına yol açmaktadır. Bunun yanı sıra, ticari amphora disiplininin önemli kitaplarına ve makalelerine atıfta bulunmadan amphora çalışmalarına bir giriş, en azından, alışılmışın dıșındadır. Örneğin, Knossos Lineer B tabletlerinde (sayfa 3), amphora kelimesinin kökeni olan a-pi-po-re-we ( $\dot{\alpha} \mu \varphi \iota \varphi о \rho \tilde{\eta} F \varepsilon \varsigma)$ kelimesinin ilk ortaya çıkışı için A.J. Evans yerine, ${ }^{3}$ temelde onu kaynak alan A.K. Şenol'un 4 referans gösterilmesi, birincil kaynaklara ulaşılmadığ 1 sonucunu ortaya çıkarmaktadır. Amphora mühürleri bölümünde (sayfa 16-17) değerli çalışmaları olan Y. Garlan, ${ }^{5}$ G. Finkielsztejn 6 veya G. Cankardeş-Şenol'un ${ }^{7}$ çalışmalarına referans gösterilmediği gibi şarap yapımı bölümünde de (sayfa 18-20) A. Tchernia ${ }^{8}$ ve J.P. Brun ${ }^{9}$ gibi bu konudaki başlıca yayınlara referans verilmemiştir. Söz konusu kaynak listesi uzundur ve kesinlikle bu kitabın temel zayıflıklarından birini oluşturmaktadır.

Yazarın, amphora mühürlerini ele aldığ sekizinci bölümde de hatalar bulunmaktadır. Sayfa 17'deki "Antalya Müzesi'nden Bazı Mühürlü Amphoralar" alt başlığında ele alınan üç amphora mührü, üzerindeki Antik Hellence yazılar nedeniyle epigrafi uzmanlarına "deşifre" ettirilmiştir. Ancak unutulmamalıdır ki üzerinde yazı bulunan her arkeolojik buluntuyu sadece epigrafi uzmanları değerlendirseydi bugün numismatik gibi eskiçağ bilimlerinin önemli bir dalı oluşmazdı. Amphora mühürleri de -numismatik gibi- ayr bir alt dal olarak çalışılmaktadır. Kitapta yer alan mühürlerin okumalarındaki sorunlar şöyledir: Figür 10'daki

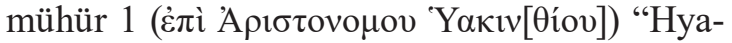
kinthios oğlu Aristonomos'un (işi eseri)" olarak çevrilmiştir ki hatalıdır. Hyakinthios, Rhodos takviminde kullanılan bir ay ismidir. ${ }^{10}$ Aristonomos ise MÖ ca. 107-88/86 yılları arasında

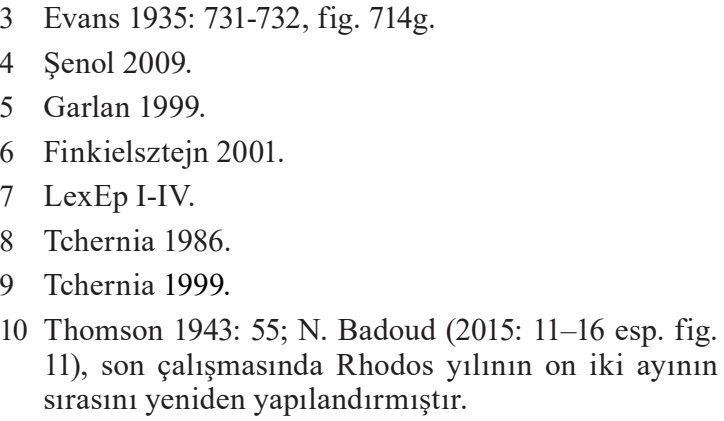

10 Thomson 1943: 55; N. Badoud (2015: 11-16 esp. fig. 11), son çalışmasında Rhodos yılının on iki ayının sırasını yeniden yapılandırmış̦tır.

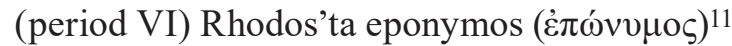
görevini yapan bir memur/rahiptir. ${ }^{12} \mathrm{Bu}$ mühür, amphoranın (aslında içeriğinin) ilgili ayda vergilendirme ișlerinden de sorumlu olan yetkili memur tarafindan kontrol edildiğini göstermektedir. Figür 12'deki mühür 3 üzerinde

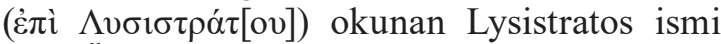
de MÖ ca. 85-40 yılları arasında (period VIIa) yine Rhodos'ta eponym görevini yapan bir memurdur. ${ }^{13} \mathrm{Bu}$ mührün amphora üzerine basılma amacı mühür 1'dekiyle aynıdır.

Yazar on dördüncü ve on beşinci bölümlerde Likya, Pamphylia ve Kilikya'daki amphora üretimiyle ilgili önceki çalışmaları özetlemektedir. Bölüm on altıda, yukarıda adı geçen bölgelerde 2011 ve 2015 y1lları arasında yazar tarafından gerçekleştirilen ve 64 gemi batığ1$\mathrm{n}$ 1 kapsayan sualtı araştırmalarının sonuçları verilmiştir. Bu önemli araştırma hakkında sadece bir harita, bir tablo ve bir sayfalık metnin ötesinde, daha kapsamlı bilgilerin verilmesi kitabın özgünlüğü açısından oldukça değerli olabilirdi.

Bölüm on yedide (sayfa 43-134) Likya, Pamphylia ve Kilikya bölgelerinde yazar tarafindan yapılan çalışmalarda tespit edilen 91 amphora (her biri bir sayfa) katalog formatında tan1tılmıştır. $\mathrm{Bu}$ bölümün ardında, aynı şekilde üç katalog daha sunulmuştur. Bunlardan ilki Antalya Müzesi'ndeki amphoralardır (bölüm 18, sayfa 135-176). İkincisi, özel bir koleksiyondaki amphoralardır (bölüm 19, sayfa 177185). “...Akdeniz Ticari Amphoralarına Örnekler (Burada yer alan amphoralar, çalışmalar kapsamında henüz bulunmamış amphoralardır)..." başlı̆̆ını taşıyan bölüm yirmide (sayfa 186-202), çalışmalarda ele geçmemiş ticari amphoraların görsellerle zenginleştirilmiş bir kataloğu sunulmuştur. Yirminci bölümden sonra kitap herhangi bir sonuç bölümü olmadan sonlanmaktadır. Yazar ilk üç katalogdaki amphoraların bir değerlendirmesini yapmadığ

11 Eponymos adı, devlet tarafından tüm belgelerine tarih vermek için kullanılan ve göreve başlamas1 yılın başlangıcına denk gelen, her yıl seçilen bir memur veya rahiptir; RE VI.1 (1907): 244-245, s. v. 'E $\pi \omega ́ v v \mu$ (J. Oehler); DNP IV (1998): 3-8. s. v. Eponyme Daiterung (A. Chaniotis).

12 Eponym Aristonomos, bk. Finkielsztejn 2001: 161, Tab. 13; kalıplar için, bk. LexEp I: 428-434.

13 Eponym Lysistratos için, bk. Finkielsztejn 2001: 162, Tab. 15; kalıplar için, bk. LexEp III: 37-38. 
gibi son bölümün bu yayın içerisinde neden yer aldığıyla ilgili ikna edici bir açıklama da yapmamıştır.

Bölüm on yedi ve sonrasındaki üç bölümde, katalog halinde sunulan amphoraların ne coğrafi ne de kronolojik bir sıralanıș izlediği görülür. Ayrıca, kataloğu yapılan amphora tiplerinin seçim kıstaslarına ilişkin yazar tarafından net bir açıklama da yapılmamıştır. Kataloglarda, her sayfanın üst bölümü bir su altı fotoğrafi, bir çizim ve bir modellemeden oluşan görsellere ayrılmıştır. Çoğu tanımlamada yetersiz olan su altı fotoğrafları çok küçük boyuttadır. Bazı amphora çizimleri de ilgili formu yansitmamaktadır (sayfa 73, 74, 116, 138, 145, 161, 174, 176). Çizimlerin yanı sıra, on yedinci bölümde kataloglanan amphoraların, sayfa 39-40'ta (tablo numarası yok) gösterilen tablodaki batıklarla ilişkilendirmenin de imkânı yoktur. Bu durum, okuyucu için buluntuların takip edilmesini zorlaştırmaktadır.

Kataloglardaki amphoraların tanımlanmasında ya da tarihlendirilmesinde bazı karmaşıklıklar da dikkat çekicidir. Sayfa 86'daki örnek bir geç Rhodos amphorasıdır ve MS 2. yüzy1la tarihlendirilmelidir (kitapta beş yüz yıllık zaman arasına, MÖ 3 - MS 2. yüzyıllar arası verilmiştir). ${ }^{14}$ Aynı durum sayfa 90 ve 121 'deki geç Rhodos amphoraları için de geçerlidir. Sayfa 136, 137, 139, 140, 154'teki Hellenistik Dönem Rhodos amphoraları MÖ 1 - MS 2. yüzyıllara tarihlendirilmişlerdir. Söz konusu amphoraların tümünü de MÖ 2. yüzyıla tarihlendirmek daha doğrudur. ${ }^{15}$ Sayfa 161'de kataloglanan ve Likya amphorası olmas1 gereken örnek ${ }^{16}$ "Kuzey Ege" kökenli olarak tanımlanmıştır. Bunun biraz tersi bir yönde, sayfa 176'da kataloglanan örnek de Güney Ege Mantar Ağızlı Amphora ${ }^{17}$ olarak tanımlanması gerekirken hatalı bir şekilde Likya amphorası olarak tanımlanmıştır. Katalog bölümlerinin en altında bulunan kaynakçada (ayrıca kitabın sonunda da farklı bir kaynakça bulunmaktadır, sayfa 206-218) çok tekrar eden bir sistem tercih edilmiştir.

14 Empereur ve Picon 1986: 117, fig. 22; Empereur ve Tuna 1989: 285, fig. 13.

15 Monachov 2005: 83, fig. 6, no. 1-2.

16 Dündar 2017, 51-60.

17 Zeest 1960: 150-152, pls. 14-16; Empereur ve Picon 1986: 112; Lawall 1995: 375, figs. 88-90.
Anadolu'nun Akdeniz kıyılarında bulunan batıklar ve amphoralarla ilgili bir kitabın denizcilik arkeolojisi ve amphora çalışmalarına önemli katkılar sağlayacağına şüphe yoktur. Bununla birlikte yayın, yöntembilim açısından, sunduğu materyallerin bir bağlama yerleştirilmesinde yetersizdir. Bölümler arasında kopukluklar yer almaktadır. Kitabın özellikle on altıncı ve on yedinci bölümleri ticari amphora çalışmaları için yeni veriler sunmaktadır, ancak konu özelinde büyük eksiklikler içerir. Ayrıca, olmayan sonuç bölümünde arkeolojik materyallerin sosyo-ekonomik ve arkeolojik yorumlarının yapılması da beklenirdi. Bunlara rağmen, yayının öncelikle merakl1larına ve ögrencilere, sonrasında ise arkeoloji camiasına bölgenin sualtı arkeolojik materyallerinin zenginliği hakkında genel bir fikir verdiği kesindir.

\section{Kaynaklar}

Badoud 2015: N. Badoud, Les Temps de Rhodes. Une chronologie des inscriptions de la cite fondée sur l'étude de ses institutions, Vestigia 63, München.

Bentz 1998: M. Bentz, Panathenäische Preisamphoren: Eine athenische Vasengattung und ihre Funktion vom 6.-4. Jahrhundert v. Chr., Antiker Kunst Beiheft 18, Basel.

DüNDAR 2017: E. Dündar, Transport Jars and Stamped Amphoras from Patara, 7th to 1st Centuries BC, Patara IV.3, İstanbul.

EMPEREUR ve PICON 1986 : J.-Y. Empereur - M. Picon, "A la recherche des fours d'amphores" In: J.-Y. Empereur, Y. Garlan (Eds.), Recherches sur les amphores grecques. Actes du colloque international organisé par le Centre National de la Recherche Scientifique, l'Université de Rennes II et l'École Française d'Athènes, Athènes, 10-12 Septembre 1984, BCH Suppl. 13, Athens, 103-126.

EMPEREur ve Tuna 1989: J.-Y. Empereur - N. Tuna, Hiérotélès, "Potier Rhodien de la Pérée", BCH 119, 277-299.

Evans 1935: A.J. Evans, The Palace of Minos at Knossos IV.2, London.

FinkIELSZTEJN 2001: G. Finkielsztejn, Chronologie détaillée et révisée des éponymes amphoriques rhodiens, de 270 à 108 av. J.-C. environ. BARIntSer 990, Oxford.

Garlan 1999: Y. Garlan, Les Timbres amphoriques de Thasos. Timbres protothasiens et thasiens Anciens, Etude thasiennes 18, Paris.

Lawall 1995. M. L. Lawall, Transport Amphoras and Trademarks: Imports to Athens and Economic Diversity in the Fifth Century B.C. (PhD diss. University of Michigan, Ann Arbor). 
LexEp I: G. Cankardeş-Şenol, Lexicon of Eponym Dies on Rhodian Amphora Stamps Vol. I, Eponyms A, Alexandrie, 2015.

LexEp II: G. Cankardeş-Şenol, Lexicon of Eponym Dies on Rhodian Amphora Stamps Vol. II, Eponyms B to K, Alexandrie, 2015.

LexEp III: G. Cankardeş-Şenol, Lexicon of Eponym Dies on Rhodian Amphora Stamps Vol. III, Eponyms $\Lambda$ to $\Sigma$, Alexandrie, 2016.

LexEp IV: G. Cankardeş-Şenol, Lexicon of Eponym Dies on Rhodian Amphora Stamps Vol. IV, Eponyms T to X, Alexandrie, 2017.

Monachov 2005: S. Ju. Monachov, "Rhodian Amphoras: Developments in Form and Measurements" In: V. F. Stolba, L. Hannestad (Eds.), Chronologies of the Black Sea Area in the Period C. 400-100 BC, Black Sea Studies 3, Aarhus, 69-95.

Rotroff 1997: S. I. Rotroff, Athenian and Imported Wheelmade Table Ware and Related Material, Agora 29, Princeton, NJ.

Rotroff 2006: S. I. Rotroff, Hellenitic Pottery. The Plain Wares, Agora 33, Princeton, NJ.

Şenol 2009: A. K. Şenol (Ed.), Taşucu Arslan Eyce Amphora Müzesi, Mersin.

TCHERNIA 1986: A. Tchernia, Le vin de l'Italie romaine. Essai d'histoire économique d'après les amphores, Bibliothèque des Écoles françaises d'Athènes et de Rome 261, Rome.

TCHERnia ve BRUn 1999: A. Tchernia - J.-P. Brun, Le vin romain antique, Glénat.

Thomson 1943: G. Thomson, "The Greek Calendar”, JHS $63,52-65$.

Zeest 1960: I. B. Zeest, Керамическая тара Боспора, MatIssla 83, Moscow.

\section{ERKAN DÜNDAR}

Orcid ID: 0000-0002-7907-1260

Akdeniz Üniversitesi Edebiyat Fakültesi

Arkeoloji Bölümü, Sualtı Arkeolojisi ABD

TR-07058 Kampüs

Antalya/TÜRKIYYE

dundarerkan@gmail.com 